\title{
Building a resource-saving society and the culture of civic saving awareness
}

\author{
Li Hong-Mei, Han Dan \\ Northeast Petroleum University School of Marxism Studies, Da Qing, China 163318
}

\begin{abstract}
With the advent of a new period of building a moderately prosperous society, the deterioration of the ecological environment, high consumption of energy, irrational industrial structure, such problems above are still the potential factors of restricting social development. To build a resource-saving society and to achieve a sustainable development is a major decision from China's national conditions. In order to build a resource-saving society and try to do one's duty, the social citizen should establish his honor to frugality perception.
\end{abstract}

Keywords: sustainable development; resource-saving society; Citizen 's saving consciousness

\section{Building a resource-saving society is the only way to achieve a sustaina- ble development}

Inorder to build resource-saving society we should improve the mechanism to provide scientific and technical support. To carry out social education means, to mobilize the whole society to save resources and make more efficient use of our resources, and this is the most convenient to support the Chinese economic and social sustainable development.

1.1 Building a resource-saving society is desirability of sustainable development for China's population, resources, environment, economic and social needs. The development of the world economic shows two major trends named the knowledge economy and the circular economy since the beginning of the new century. In the process of economic operation, material resources is replaced with intellectual resources, that is a knowledge-based economy and has to achieve economic activity change of knowledge. The circular economy is the use of natural resources in accordance with the laws of ecology and environmental capacity which is to realize the economic activities of the ecological steering. In Western countries, the development of circular economy and building a resource-saving society has become a tide or a trend. [1] Savings for building a resource-saving society is relative to waste, we must clearly recognize that China's economic development will continue to be based on the mass consumption of natural resources for quite a long period of time, and thus improving the efficiency of resources utilizationthe, reduction of low efficiency of waste and dealing well with the relationship between resource utilization and ecological environment are the an only good development way. For a long time, China attaches great importance to saving social construction, and achieves positive results National Bureau of Statistics released the data, and the country's total energy consumption reached 3.25 billion tons of standard coal, up 5.9\% . 10,000 GDP energy consumption fell $4.01 \%$ in 2010 . However, China's total energy consumption in 2011 reached 3.48 billion tons of 
standard coal, which had an increase of $7.0 \%$ over the previous year, and the $\mathrm{Na}$ tional's 10,000 GDP energy consumption fell $2.01 \%$. The total energy consumption in 2011 grew faster than the 1.1 percent in 2010, and 10,000 yuan of gross domestic product (GDP) energy consumption decline was slower than in 2010, two percentage points. It shows that China is currently in the rapid advance stage of industrialization and urbanization, energy, resource demand is growing at an unprecedented rate. Especially in recent years, China's high economic growth built in high energy consumption, the sources of energy, fresh water, land, mineral and other resources to further highlight: on the one hand the sources of energy, resource supply and demand tensions already very apparent, most of the mineral resources per capita is less than half the world average level; energy resources supply and demand tension trend has very obvious, most of the mineral resources per capita is less than half of the world average; On the other hand, in our energy, resource constraints, while the waste are becoming increasingly serious. With the further expansion of China's economy, residents' consumption structure escalation, resource supply and demand in China and growing environmental pressures. Therefore building a resource-saving society is to ensure that the objective need of sustainable development of China's economic and social health.

1.2. Building a resource-saving society is a long-term task and a comprehensive work.

According to the country "1025" energy plan, the "1025" period in China's energy consumption controls in 41 billion tons Biao Mei left and right sides and the power consumption controls in 6.4 trillion KWH. Despite the plan is strictly able to control the various local government's total energy consumption in- creased, but we should also see the construction of a resource-saving, proenvironmental society is not only related to the economic and social fields, but also related to people's life, it still has a lot of work to do and aslo need many system, measures keep up with for building a resource-saving, pro-environmental society. Our country is necessary to take effective measures to achieve the transformation of economic growth mode from extensive to intensive; should also increase the economic structural adjustment efforts, promote the optimization and upgrading of industrial structure, promoting national economic and social information; necessary to vigorously develop the circular economy, from resource extraction, production and consumption, waste utilization and social consumption sectors, accelerate the comprehensive utilization of resources and recycling; should pay close attention to the development of the coordination of national resources rational development and utilization planning and sound policy system to achieve economic and social resources and environment development; necessary to strengthen the macro-planning and guidance mechanisms to conserve resources, the formulation of policies and laws, should do a good job in the organs, enterprises, business groups, households to save a drop of water, once electricity saving propaganda and guidance work, saving is regard as a strategic work related to China's economic and social development, as well as one of China's each citizen's behavior. It's not an easy thing to build a resource-saving society, the apparent effectiveness of saving society perhaps need many years' efforts, therefore we must firmly establish this kind of thought and consciousness from now on, let the conscious of building a resource saving society ideas into each person's action, so that saving becomes a habit. 


\section{Cultivating the awareness of citi- zens towards conserve resources and protect the environment, from detail to the concept of saving}

2.1. It's necessary to improve the nation's hardship resources and environmental protection awareness, regard the construction of a resource-saving and the pro-environmental society as their responsibility and obligation. Citizen is the main body of building a resource-saving society, the citizen has the rational rights and sense of responsibility through the cultivation of citizen consciousness, that will fundamentally promote the process of saving society. Civic consciousness is a kind of modern consciousness which includes the sense of responsibility of the citizens of the state and society. To construct a economical society, involves the content is closely linked with everyone, it is through the whole society of different classes of people trying to achieve. As a citizen, he is in the economical society and participates in the social production and living activities, in a sense, it can be said that when everyone cares about, participation, promote economy, that is a resource-conserving society built date. In order to create the good environment of the premise, we must enhance the whole nation's resources suffering consciousness and environmental protection consciousness and set up the concept of resource conservation in the whole society. The environmental crisis has been involved in each individual life on Earth. The phenomenon happened aroud the world such as the green house effect, ozone holes and acid rain is over the force of nature warning line through the research by HermanWear in 2001. It is an inherent balance between the production and creative process of the human society and the substance of the environment and the energy conversion process, if it exceeds the environmental carrying capacity, this balance will be broken, not even repeat. [2] It's everyone's duty to protect the environment, start from me, start from now and start from the things nearby to overcome the bad habits of destorying the environment, thus achieve the harmony and unity of man and nature. At present, it doesn't have a strong awareness of the environment, and the societyis also lacking of civic awareness for promoting proenvironmental society. The environmental pollution is an urgent requirement to adjust and standardize the behavior, the mentality of people in the environmental aspects of new environmental ethics.

2.2. Carry forward the Chinese national thrifty virtue, advocate the economizing culture, and eliminate the consumption patterns and values of materialism

The traditional virtues of the Chinese nation has always advocated diligence and frugality, Hing home like a needle pole, ruining watery push sand. Both Confucius and Confucianism have the level of consumption, or Lao tze and Taoist proposed without consumption, both tend to dismisses extravagantly honors thriftily, which reflects the ancient Chinese social and economic development level of social consumption restriction. Consistent philosophy of the ancients thrift Heaven, emphasizing the harmony of man and nature, so as to protect and conserve natural resources, promote ecological health, harmonious and sustainable development of the purpose of this wisdom for us to build a saving social ethics resources and moral support. Confucianism emphasizes the relationships should be treated differently in spite of the thrif of Chinese traditional culture, the negative effect is pomp in the consumption process, even if the economy isn't good ,the human consumption is not neglect. This excessive consumption will have a hotbed, so that the austerity thinking will encounter obstacles at sometimes. Our energy saving consciousness is still very weak, there are many not scientific, 
not healthy, not civilized consumption patterns, resulting in waste of resources is quite amazing. Today's saving is to develop a more scientific and reasonable consumer attitudes and habits, thus saving the glorious, shameful waste of social morality. It can be used only let the savings become a tradition, a habit, put the saving ideas into the social cultural. It's a part of the advanced national culture and the fine national tradition to advocate the saving way of life, and regard it as an important part of the conservation-oriented society[3]Set up the saving glory, waste shameful culture idea set the sacrifice descendants living conditions of shame for social fashion, is the current activities to protect the ecological environment of the important moral impetus.

2.3. Absorb some beneficial connotation of economical from the modern developed countries and advocate the economical way of life

Life consumer is not a small figure. Most western are very saving in their daily lives, Such as the British use the paper and mail to the presentation data, used to accumulate up never discarded stay to do the next thing with the print on the back. Another case in primary school textbooks, younger students often took the highgrade, until it should not be reused till. Many Swedes work does not drive a car, because they think a person driving a car trip is too wasted under special circumstances. Germany is the green one of the leading countries in the world today. Leading mainly reflected in two aspects: First, the strong development of environmental technologies and applications, second, the public environmental concern and participation. German household in front of the trash can reflect the German environmental awareness. The first arrived in Germany, will inevitably have a trash can in front of colorful curiosity. The residential front of generally have four bright yellow blue black green trash, are affixed to the a straightforward waste classification pattern. Stated on the yellow barrels loaded scrap metal, collect waste paper box and plastic blue barrel, black barrel, ordinary garbage, trash a new family of green barrels collect new classification from ordinary garbage out tea and shells biowaste. German provisions are very complex in the trash in fact, but most Germans work in accordance with the provisions to be strict in theirs demands. Waste separation and recovery is conducive to waste recycling and reduce waste pollution, while it can increase economic efficiency. Implementation of garbage separation and recovery is just a microcosm of the importance of environmental protection in Germany. It can urge the whole society to save resources from the conservation awareness of developed countries. It's a kind of reference for our country which is ravaged by resources.

In short, we must enhance the sense of hardship under the growing situation what the development of economic depend on the energy, and build a huge network of building a resource-saving society by our will and action. Guide the consumption pattens of change by the consumption concept of conserve resources and gradually form a civilization and saving patterns of behavior, form a good habit that everyone has a sense of responsibility and put forth our strength for building a resource-saving society.

\section{References}

[1] Y.W. Deng. Establish circular economy needs to solve what problem. Economic Daily. pp.31-32, 2006,06

[2] H. Daley. Beyond the growth: the economics of sustainable development[M]. Shanghai: Shanghai translation publishing house, 2001.

[3] X.W. Du. thinking on building a resourceconserving society. Shandong Economic Strategy Research. pp.30-32,2009,11. 